In this research, the authors seek to advance the understanding of how marketing can facilitate the new product design process. They focus on how designers' use of a specific cognitive process, visual mental imagery, can influence the customer appeal of a design. The authors present a conceptual framework for examining how visual imagery might influence the customer appeal of a design output. This is followed by two experiments that test the hypotheses that flow from the proposed model. The experiments manipulate the type of visual imagery used and the incorporation of the customer in the imagery invoked and then examine its effects on the usefulness, originality, and customer appeal of the resulting design. Consistent with the framework and the proposed hypotheses, the findings show that including the customer in imagination visual imagery during the design process has a greater effect on the usefulness of the design produced than including the customer in memory visual imagery. The results also show that imagery based on imagination results in more original designs than imagery based on memory. Most important, the use of bounded imagination, which results from the incorporation of the visual images of the customer in imagination imagery, leads to the creation of designs that are more appealing to the customer. The findings are integrated into a discussion that clarifies the role of visual imagery in design and underscores the potential of this cognitive tool in the new product

design process.

\title{
The Use of Visual Mental Imagery in New Product Design
}

The failure rate for new products has remained steady at $35 \%$ to $45 \%$ for more than 25 years (Business Week 1993; Crawford 1987). Recent research in marketing (e.g., Wind and Mahajan 1997) has sought to address this problem by highlighting the need for new marketing-oriented approaches. Research indicates that, to be successful, new products must offer something novel to the customer (Angelmar 1990; Cooper and Kleinschmidt 1987). For example, the innovative Reebok "pump" design that inflates small

*Darren W. Dahl is Assistant Professor of Marketing, Faculty of Management, University of Manitoba (e-mail: dahld@ms.umanitoba.ca). Amitava Chattopadhyay is Associate Professor of Marketing, University of British Columbia (e-mail: chatto@interchange.ubc.ca). Gerald J. Gorn is Professor of Marketing, Hong Kong University of Science and Technology, and Advisory Council Professor of Consumer Behavior. Department of Marketing. University of British Columbia (e-mail: mkgorn@uxmail. ust.hk). The authors thank Joe Alba. Peter Darke, Gita Johar, Jaideep Sengupta, Charles Weinberg. the three JMR reviewers, and the editor for their helpful comments and suggestions. The financial support from R.G.C.. Hong Kong, and the Social Sciences and Humanities Research Council of Canada is gratefully acknowledged. To interact with your colleagues on specific articles in this issue. see "Feedback" on the $J M R$ Web site at www ama org/pubs/jmr. pockets of air in the heel of basketball sneakers has led to more than $\$ 200$ million in revenues (Dumaine 1991). The product's originality helped it stand out from the crowd and created a competitive advantage (Kotler and Rath 1984). Originality, however, is not the only criterion for new product success, as is evidenced by the recent, highly publicized failure of the Newton personal digital assistant (PDA) from Apple Computer Inc. (Elstrom 1996). Newton was the first PDA to recognize handwritten characters and achieved a high level of recognition accuracy for single characters. Although Apple regarded this recognition ability as superior (Weiman and Moran 1992), it proved inadequate in the eyes of the customer (Johnson 1993; Orr 1993). Even assuming a $97 \%$ level of recognition accuracy at the character level, a seven-digit telephone number would be processed incorrectly approximately $20 \%$ of the time, with longer entries (names with addresses and phone numbers) incorrect most of the time. I Therefore, to appeal to the customer and be successful, a new product must not only be original, as the Newton undoubtedly was, but also useful, that is, success1993).

The trade press reported word accuracy levels of $70 \%$ to $80 \%(\mathrm{Or}$ 
fully meet some important need(s) of the customer (Baxter 1995; Pugh 1996), something the Newton failed to do.

An important step in the new product development process is product design (Urban and Hauser 1993). The development of a product design concept commonly is viewed as one of the most important phases of the product development process, because the decisions made at this stage strongly bear on all subsequent phases of product development (Roozenburg and Eekels 1995). When designing new products, the goal is to give the product physical and psychological attributes that will lead to success in the marketplace (Oakley 1990; Urban and Hauser 1993). We examine one way in which the design process can be managed to generate designs that will appeal to the customer. In particular, we focus on visual imagery, one of the central cognitive inputs for the design process (Lorenz 1990; Roozenburg and Eekels 1995).

We also focus on a particular design mission for a consumer product. As Bahrami and Dagli (1994) note, the mission given to designers often varies. For example, Ulrich and Eppinger (1995) distinguish between a designer's narrower mission of trying to build a better pneumatic nail tool for fastening wood, targeted at the high-end consumer market, versus a broader one of trying to find better ways to fasten wood together. In this research, we focus on the former type of design situation, in which the designer is asked for a product improvement that will meet the needs of a particular set of customers. Furthermore, we focus on functional performance in product design, as opposed to the product's aesthetic qualities or appearance.

Product designers are encouraged to use visual mental imagery when coming up with their proposed designs, with design courses explicitly training them in visualization (cf. French 1994). Downing (1992, p. 442) notes, however, that "very little research has been conducted that directly explores the nature of the mental image and the implications for its use in design." We take as our starting point the notion that visual imagery leads to improved designs and expand on it in two ways. We examine the effects on design output of (1) two types of visual mental imagery, memory and imagination, and (2) whether the visualization contains images of the target customer.

From a theoretical perspective, our research extends the existing marketing and design literature on the role of imagery. First, though prior research in marketing has acknowledged the distinction between memory and imagination imagery (Childers and Houston 1983; Ellen and Bone 1991), it has not examined the implications of this distinction. By showing that these different types of imagery can have different impacts on the design outcome. we show the value of this distinction in the context of new product development. Second, our investigation of customer incorporation in the visualization used during the design process is new to the marketing and design literature. Focusing on the customer is central to the marketing concept. Our research supports and extends this basic premise by specifically studying how visualization of the customer during the design process can influence the resulting design output.

To acquire a better understanding and confirm our intuition regarding the use of visual mental imagery in design, in-depth interviews were conducted with product designers from ten randomly selected product design firms of differ- ent sizes who were experienced in the design of consumer products. In each of the ten interviews, the designer identified the importance of using visual mental imagery in the design process. Their responses suggested that they used memory imagery as their main idea source, because they relied on existing products in the marketplace, product ideas conveyed to them by their clients, and prior experience with similar products. Only one of the designers indicated that he liked to look at unrelated product forms to spark new ideas.

All of the designers indicated the importance of identifying and understanding the end user, though most believed that there should be improvement in this area. They noted that putting the customer at the center of the design process was still not a norm throughout the industry and that clients often were unwilling to put resources toward this goal. When asked about their visualization, none of the designers indicated that he or she used images of the customer as a tool to enhance the design effort. However, three of the ten designers did indicate that they visualized themselves as the customer when designing. Therefore, though designers recognize the importance of visual imagery, no explicit distinction is made between memory and imagination visual imagery, a distinction we believe is important and that we study. Furthermore, designers recognize the importance of a customer focus but believed that, at that point, they did not focus adequately on the customer or include the customer in the visualization process, something we examine in this research. Thus, our research assesses issues of relevance to both marketing and design practitioners.

In the next section, we discuss relevant research on visual mental imagery in the design, marketing, and psychology literature, present a conceptual model of how visual mental imagery influences the customer appeal of the product designed, and propose a set of hypotheses. We then present an experiment that tests our hypotheses. The generalizability of our findings are tested in a follow-up experiment. We conclude with a discussion of the results and directions for further research.

\section{CONCEPTUAL MODEL}

\section{Visual Imagery as a Design Tool}

Visual mental imagery. MacInnis and Price (1987, p. 473) define visual mental imagery as "a process by which visual information is represented in working memory." Visual mental images are functional, quasi-pictorial representations, the special properties of which can influence cognitive processing. Specifically, they enable the generation, interpretation, and manipulation of information through spatial representation. Their importance has been recognized in marketing (e.g., MacInnis and Price 1987), engineering design (e.g., French 1994), and other areas as well, including art design, industrial design, and architecture.

Types of visual mental imagery. Although reference to visual imagery is made in the design literature, no formal distinction is made between different types of visual mental imagery. In marketing, this distinction has been made, and some scholars (e.g., Childers and Houston 1983; Ellen and Bone 1991) have gone a step further and referenced Richardson's (1969) taxonomy of types of imagery from the psychological literature. However, their empirical research focuses only on one of these types of imagery, namely, memory imagery. 
The identification of different types of visual mental imagery has a rich research tradition in psychology. An important early distinction in imagery type (e.g., Ogden 1913; Perky 1910) that also is reflected in more recent research (e.g., Horowitz 1983; Kosslyn 1994; Richardson $1969,1983)$ is the distinction between images based on imagination and those based on memory. Memory images refer to events or occasions that have been personally experienced or observed (Perky 1910). An example of a visual memory image is the creation of a visual image of the contents of the breakfast a person ate yesterday. An imagination image differs from a memory image in that, instead of recalling a prior experience for the image, a new, neverbefore-experienced event is constructed (Perky 1910). For example, a breakfast visual image could be imagined in which the contents of the breakfast were all colored blue. Note that the imagination image also involves prior memory (i.e., breakfast and the color blue); however, it recombines these memory images in a new and previously unseen way. ${ }^{2}$ Differentiating between types of imagery has been found to be important in learning, mood and affect, neuropsychology, and problem-solving (e.g., Adeyemo 1990 , 1994), an area related to this research.

The distinction between the use of memory and imagination imagery is important in a product design context as well. By definition, imagination imagery is novel, because it involves the creation of previously unseen images. Adeyemo (1990) has demonstrated the capacity of imagination imagery to facilitate innovative problem solutions. This capacity would stem from a broadened solution space when imagination imagery is used. In contrast, memory imagery is confined to previous experience. Although images based in memory can provide a reference point for design (Downing 1992), a reliance on memory imagery might limit the full potential of visualization.

The importance of the customer. A customer orientation is central to marketing (cf. Blattberg and Deighton 1996; Deshpandé, Farley, and Webster 1993). Marketers have developed many approaches for bringing customer needs and wants to the attention of the designer (e.g., Griffin and Hauser 1993; Urban and Von Hippel 1988; Von Hippel 1978, 1986). Although this has led to the successful development of many new products, as Bailetti and Litva (1995, p. 3) note, "despite all best efforts, the design process often leads to the introduction of products that do not meet customer expectations."

One possibility is that, when designing products, designers are not always able to incorporate information about the customer effectively. Rifkin (1994, p. 10; see also Leonard and Rayport 1997) has suggested a move toward "empathic design," in which the voice of the customer "comes out of understanding users' needs through empathy with their world." Empathy might result from incorporating the customer in the content of the visual mental imagery used when designing a product. Incorporating the customer in design imagery refers to the actual imaging of a customer with the product. This form of imaging could involve images of the customer as an "actor," using product prototypes, interacting

2Morris and Hampson (1983) note that memory and imagination can be put on a continuum. At one end. there are pure memory images. At the other end, though memory is involved. it serves as a springboard for the imaginative constructions that predominate. with specific aspects of a design, or using previous designs on which the designer is attempting to build. We propose that including the customer in the visual mental imagery used during the product design process affects the design output. Furthermore, we propose that the impact of including the customer in the visualization depends on the type of visual mental imagery invoked. These propositions are developed more fully in the next section.

\section{The Design Output: Usefulness, Originality, and Appeal}

Thus far, we have concentrated on two major inputs for the design process, the type of visual imagery that is used by the designer (memory versus imagination) and the content of the imagery (whether the customer is incorporated). These inputs to the design process cannot, however, be discussed in isolation. To establish a context for their role in product design, we must examine their impact on the outputs of the design process.

The central goal of the product design process is to create products that appeal to the end user (Bloch 1995; Kotler and Rath 1984). The question then becomes, On what factors does customer appeal depend? The literature on new product success suggests that a product must have a competitive advantage to appeal to the customer. Consistent with the literature, we define competitive advantage as the ability to provide something new, original, and useful to the customer (Angelmar 1990; Cooper and Kleinschmidt 1987, 1990; Davidson 1976; Song and Parry 1997). In this research, which deals with concept design, we focus on originality and usefulness as drivers of customer appeal. We recognize that at later stages (e.g., test marketing), other variables also would be important, such as economic cost. Figure 1 presents our conceptual model of how imagery type and content influence the usefulness, originality, and customer appeal of a design.

Design usefulness. Compared with memory imagery, imagination and its playful imagery manipulations are likely to lead to a numerically large and diverse set of images and to more original designs, as we predict subsequently with our second hypothesis (e.g., Finke, Ward, and Smith 1992; Roskos-Ewoldsen 1993). However, a free and uncon-

Figure 1

CONCEPTUAL FRAMEWORK OF HOW CUSTOMER INCORPORATION AND IMAGERY TYPE DRIVE CUSTOMER APPEAL

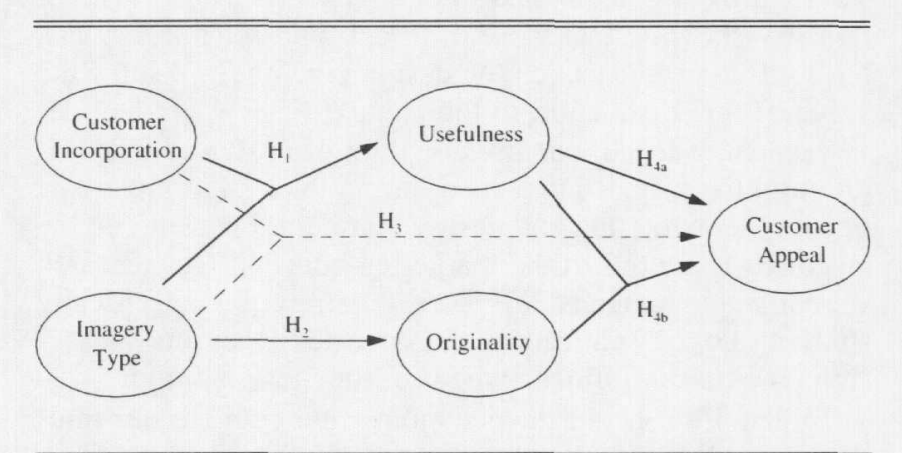

*The solid lines represent direct relationships. The effects of customer incorporation and imagery type on customer appeal are mediated by usefulness and originality. We use a dotted line to represent this relationship. 
strained flight of imagination imagery also could lead to fanciful design ideas that have little relevance to the customer.

Putting the customer into the design process imagery should ensure that all design activity remains centered on the customer. Previous discussions of customer involvement in design (e.g., Bailetti and Litva 1995; Palmiter et al. 1994) have pointed to a need for designers to "keep the customer in their thoughts as they design ... the producl" (Palmiter et al. 1994, p. 129). Including the customer in imagination imagery constrains the solution space by providing appropriate boundaries to focus the designer's imagination. This use of bounded imagination brings realism into the design process by providing relevant guidelines for the imagination imagery. The resulting design process should be able to fulfill customer requirements better and create a product that is useful and appealing to the end user (Bailetti and Litva 1995).

We anticipate that customer incorporation in memory imagery will have less of an effect. Previous research in design has shown that relying on memory during the design process may lead to suboptimal outcomes (Jansson and Smith 1991; see also Smith, Ward, and Schumacher 1993). Jansson and Smith (1991) asked subjects to come up with new product designs, giving the subjects in what they call the fixation group some example solutions. They find that, relative to the control group, those given example solutions tended to fixate on the examples and stuck closely to them in the designs they created. We expect that memory forms of imagery will create a fixation point. Including the customer in what is already a more constrained solution space should have less of an effect on the usefulness of the design output. Also, designs in the marketplace are likely to have at least some usefulness, or they would not likely be on the market. Therefore, even without instructions to visualize the customer, the product designs retrieved by designers from memory are likely to have some customer utility, thus reducing the scope for improvement through customer incorporation in the visualization. This, of course, would be more true for established products that have been in the marketplace for a long time than for really new products. Here, we focus on wellestablished products. We hypothesize the following:

$\mathrm{H}_{1}$ : Including the customer in imagination visual imagery during the product design process will have a greater effect on the usefulness of the designs produced than including the customer in memory visual imagery.

Design originality. As we discussed previously, imagination imagery is likely to lead to a more diverse set of images. This should lead to more original designs. In support of this idea, Adeyemo (1990) shows that, in a creative problemsolving exercise, the use of imagination imagery led subjects to develop more creative and original solutions to the experimental problem. In contrast, the dependence of memory imagery on previous experiences constrains playful imagery manipulations and reduces the diversity of images generated and, therefore, the originality of design solutions (Jansson and Smith 1991). Thus, we hypothesize the following:

$\mathrm{H}_{2}$ : When designing a product, the use of imagination visual imagery, compared with the use of memory visual imagery, will result in product designs that are more original.
Previous research does not provide a clear picture of how incorporating the customer in the visual imagery used in the design will affect the originality of the design output. Therefore, we offer no formal hypotheses regarding this potential relationship, though we examine such effects empirically.

Creating appealing designs. The central goal of the product design process is to create products that appeal to the end user (Kotler and Rath 1984). According to our conceptualization, at the early stages of the product development process, customer appeal depends on the usefulness and originality of the product design (Cooper and Kleinschmidt 1987. 1990; see also Figure 1). Products that are useful to the customer, that is, that satisfy their needs, are more appealing (Pugh 1996). Products that are original will be more liked, but only if they are useful as well. As the case of Apple's Newton illustrates, products that are original but not useful are not likely to appeal to the customer. However, a product that is useful in addition to being original should be well liked (Cooper and Kleinschmidt 1987). Our conceptualization also suggests that originality and usefulness, in turn, depend on the type of imagery and whether the customer is incorporated in the visualization (see Figure $1, \mathrm{H}_{1}$, and $\mathrm{H}_{2}$ ). Taken together, this suggests that customer appeal depends on the interaction of imagery type and customer incorporation and that this effect is mediated by the usefulness and originality of the design. More specifically,

$\mathrm{H}_{3}$ : The most appealing designs will be produced when both imagination imagery is used and the customer is incorporated in the imagery.

$\mathrm{H}_{4 \mathrm{i}}$ : The effects of imagery type and customer incorporation on customer appeal will be mediated by a direct effect of usefulness.

$\mathrm{H}_{4 \mathrm{~b}}$ : The effects of imagery type and customer incorporation on customer appeal will be mediated by an interactive effect of usefulness and originality.

\section{EXPERIMENT I}

Two experimental factors (imagery type and customer incorporation in visualization) were manipulated in a between-subjects design. There were two levels of imagery type (memory and imagination). Because previous research has indicated that it is difficult for the designer to focus on the customer (e.g., Bailetti and Litva 1995), we used two operational manipulations of customer incorporation. Thus, there were three levels of customer incorporation (no customer incorporation, customer incorporation instruction, and customer incorporation instruction plus training). A single control condition that received neither manipulation also was included. Thus, the design had seven cells ([2 imagery type $\times 3$ customer incorporation] +1 control).

\section{Product Designers}

Designers participating in the study were 140 undergraduate engineering students. They all had completed coursework in design fundamentals and were recruited in design engineering classes through announcements offering $\$ 10$ for participation. Previous research in product design has used engineering students (e.g., Jansson and Smith 1991). 


\section{Product}

The product chosen for the design task was a car jack for seniors (age 60 years or older). Seniors were chosen as the target customers because they represented a population that was distinctly different than the designers. This was done to represent the real-life situation in which designers often design products for customers different than themselves. On the basis of informal discussions with seniors, a car jack was chosen as the product for our study, because seniors reported having difficulty using those jacks currently available.

\section{Independent Variables}

Manipulation of imagery type. Visual mental imagery type was manipulated by instructing designers to rely on images based on either imagination or memory during the design task. These instructions were developed through pretesting. In the memory imagery condition, designers were instructed as follows:

In solving design problems, many designers find that using past memories to form visual images (pictures in the mind) of potential designs can help them produce innovative and effective designs. Digging deep into your memory and visualizing car jacks that you have previously seen may help in the development of design solutions. In producing your design, please try to use this type of visual strategy.

In the imagination imagery condition, designers were instructed to go beyond previously seen images, as follows:

In solving design problems, many designers find that using imagination to form visual images (pictures in the mind) of potential designs can help them to produce innovative and effective designs. Using imagery that goes beyond car jacks that you would normally see can help in the development of design solutions. In producing your design, please try to use this type of visual strategy.

Manipulation of customer incorporation. In the no customer incorporation condition, designers received no instructions to visualize the customer. As we mentioned previously, two approaches to encourage customer incorporation during visualization were used. These were developed on the basis of pretesting. In the first approach, designers were instructed to incorporate the customer in their visualization, as follows:

A useful strategy in design involves visualizing the potential customer of the product. Seeing in your mind an elderly person being involved with and interacting with the proposed product design can assist the development of the design solution. In producing your design, please try to use this visual strategy.

In the second customer incorporation condition, designers were given a five-minute training task before receiving either the imagery or customer incorporation instructions. The training exercise used a guided imagery procedure. This involved the designers reading a short story about a young adult putting together a television stand. As the designers read the short story, they were instructed to stop after reading each sentence in the story and try to picture in their minds the events about which they had just read. After completing the training exercise, designers were given the appropriate imagery instructions, depending on the condition to which they had been assigned, as well as the instructions to visualize the customer in the design task.

Control group. The control group was not given any instructions to use visual imagery, that is, they received neither imagery type nor customer incorporation instructions. Given their academic training, we expected that the designers would use visual mental imagery spontaneously and that this visual imagery would be primarily memory rather than imagination imagery. If this turned out not to be the case, any differences we might find between the imagination and memory imagery conditions might be attributed to our memory imagery treatment hurting and the imagination treatment encouraging the production of more original and appealing designs.

\section{Procedure}

Designers participating as subjects were tested individually. The group that received the training task (customer incorporation instruction plus training) received the training first. Designers in all conditions then received the instructions for the design task. They were instructed to design a car jack for elderly adults (age 60 years or older) and produce a "thumbnail sketch" of the central aspects of their design idea. They were told to disregard any constraints (e.g., economic, material, regulatory) as they developed their idea. On the basis of pretesting, they were given 30 minutes to complete the task. Designers in the control condition proceeded to the design task at this point. The remaining designers received the imagery type (imagination or memory) treatment. One-third of the subjects in each of the imagery type conditions, who had been assigned to the no customer incorporation condition, proceeded to the design task. The remaining two-thirds received the customer incorporation instructions, followed by the design task. Half of these subjects had received the prior training in customer incorporation, as we noted previously. Note that the training task was given before the main task. This precluded the possibility that, during training, subjects would be thinking of the design they would later have to create, leading to them having more experience with designing car jacks than those in the other conditions. After completing the design task, designers filled out a short questionnaire, were debriefed, and were paid for their participation.

\section{Manipulation Check Measures}

The questionnaire completed by the designers started with an open-ended measure that asked them to describe any mental pictures they had during the design exercise. These responses were used to assess the success of the customer incorporation manipulation. Next, the designers were asked to complete three seven-point scales that sought to determine the nature and form of their visualization. Designers were asked how hard they were trying to use visual imagery in producing their design ("not very hard" [1] to "very hard" [7]), to what degree they used mental pictures of previously seen car jacks ("not very much" [1] to "very much" [7]), and to what degree they used mental pictures that went beyond a "normal" car jack ("not very much" [1] to "very much" [7]). Finally, they completed an open-ended question that asked what they thought the purpose of the study was. 


\section{Dependent Measures}

Target customer judges. When designing new products, the goal is to appeal to a potential user. Therefore, responses to the dependent measures were obtained from a sample of elderly judges who were recruited from local senior citizen centers. To qualify, judges were required to have a valid driver's license and have driven a vehicle in the past year. A separate sample of judges evaluated all of the 140 designs for each of the dependent variables of interest (originality: $n=14$ judges, useful: $n=16$ judges, appeal: $n=12$ judges) . Pretesting indicated that this was a reasonable task for an individual judge to complete; it took between one and a half and two hours, including breaks. Separate judges were used for each dependent variable to eliminate shared method variance (see Olney, Holbrook, and Batra 1991).

Twenty booklets were prepared, each with a different random order of the 140 designs. Judges were randomly assigned one of the booklets. Judges worked individually and went through the booklet at their own speed, rating each design along the three items that pertained to the construct they were assigned. They were paid $\$ 20$ for their participation.

Target customer judgements. Originality, usefulness, and appeal each were measured by a three-item, seven-point semantic differential scale drawn from previous research (Andrews and Smith 1996; Besemer and O'Quin 1986; Kardes 1986; Mano and Oliver 1993). The three items composing the originality scale were "unique" (7) to "ordinary" (1), "original" (7) to "commonplace" (1), and "fresh" (7) to "routine" (1). Items for the usefulness scale were "useful" (7) to "useless" (1), "effective" (7) to "ineffective" (1), and "worthwhile" (7) to "worthless" (1). The customer appeal scale was composed of "appealing" (7) to "unappealing" (1), "likeable" (7) to "not likeable" (1), and "desirable" (7) to "undesirable" (1).

\section{RESULTS}

\section{Preliminary Analyses}

Manipulation checks. The type of imagery used during the design task was examined with scale measures of memory and imagination image usage. As we noted previously, because memory would be involved in both the memory and imagination conditions. we did not expect any significant differences between these conditions on the memory image usage scale. A two-way ANOVA with imagery type and customer incorporation as the two independent factors showed that there were no significant effects $\left(F_{s}(1,134)<1\right) .{ }^{3} \mathrm{~A}$ two-way ANOVA for the imagination image usage scale, with imagery type and customer incorporation as the independent factors, revealed only a main effect for imagery type $(\mathbf{F}(1,134)=8.17, p<.01)$. Designers in the imagination condition used imaginative images to a greater extent (means: imagination $=5.11$, memory $=4.30$ ). For these measures, the control condition was not significantly different than the memory condition $(p s>.10)$.

Open-ended responses, used to assess the success of the customer incorporation manipulation, were coded by a

'For the ANOVAs and planned contrasts, to obtain a better estimate of within-cell error. we use data from the control condition i.t addition to the dala from the six experimental conditions (Keppel 1991). Using the error term from just the six experimental conditions does not change our results substantively. research assistant to identify the number of distinctly different images involving the customer that were used by the designer. As we expected, a two-way ANOVA indicated a significant main effect for the customer incorporation manipulation $(F(2,130)=30.37, p<.001)$. Contrasts across the three levels of customer incorporation revealed significant differences $(p s<.01)$ between each of the three conditions (means: no customer incorporation $=.59$, customer incorporation instruction $=1.50$, customer incorporation instruction plus training $=2.69$ ). The control condition did not differ significantly from the condition that received no instructions to incorporate the customer $(p>.10)$.

It was also considered important to establish that the designers across all conditions made an equal effort on the visualization task. The two-way ANOVA on the scale that assessed how hard the designers tried to use imagery indicated that there were no significant differences across the experimental conditions (all Fs $<1$ ). In addition, the control condition did not differ from the manipulated conditions in efforts to visualize $(p>.10)$.

Finally, designers' responses to the question related to the perceived purpose of the study were examined. No designers were aware of the experimental hypotheses, and none suspected that the study had anything to do with differences in the nature of visualization during the design process.

Reliability assessment of judges' ratings. Coefficient alpha was used to assess reliability. Following Olney, Holbrook, and Batra (1991), reliability was assessed for individual items across judges, scale indices within judges, within-judge scale indices across all judges, and the aggregate scale index composed of the mean of all judges on each item.

The alphas for single-item interjudge reliability on each of the nine scale items ranged between .70 and .77 . Scale indices for each of the 42 individual judges ranged from .75 to 1.00 . The index formed by summing the three-scale items for each construct within each judge and then calculating the interjudge reliability on that sum produced reliabilities of .75 for original, .78 for useful, and .71 for appeal. Finally, the aggregate index composed of the average of the scale indices across all the judges was $.98,1.00$, and .99 for the original, useful, and appeal items, respectively.

To assess the validity of the three construct measures, the mean scores across the judges for each of the nine items that make up the three constructs were subjected to principal component analysis, followed by varimax rotation. As we expected, a three-factor solution was obtained (variance explained $=98 \%$ ). The three items measuring each construct loaded on a separate factor (all loadings $>.91$ ). Follow-up confirmatory factor analysis revealed that the three-factor model provided an acceptable fit (Bentler-Bonett normed fit index $[\mathrm{NFI}]=.964$, comparative fit index $[\mathrm{CFl}]=.973, \chi^{2}$ $(25)=99.85, p<.001$ ), because the fit indices exceeded .90 , the benchmark for acceptable fit (Bentler and Bonett 1980). In addition, neither the single-factor model (NFI $=.421, \chi^{2}$ $(27)=1629.78, p<.001$ ), nor a two-factor model, in which the items for the usefulness and customer appeal constructs were combined, fit the data well $\left(\mathrm{NFI}=.641, \chi^{2}(26)=\right.$ $1010.26, p<.001)$. For the hypotheses tested subsequently, the mean score across the three items measuring each construct was used as the operational measure. 
Memory versus control. As we noted previously, those in the control condition used the same type of imagery as those in the memory condition (see the manipulation check results). This should result in the designs produced being similar to those produced in the memory condition in terms of originality, usefulness, and customer appeal. A series of planned contrasts compared those in the control condition with those in the memory imagery, no customer incorporation condition. The results showed that the designs produced did not differ in terms of originality $(F(1,138)<1$, means: control $=3.96$, memory $=3.82)$, usefulness $(F(1,138)<1$, means: control $=3.10$, memory $=3.12$, and customer appeal $(F(1,138)<1$, means: control $=3.32$, memory $=3.27)$. Thus, the findings with respect to the main hypotheses are driven by the superiority of providing explicit instructions to use imagination imagery, not because instructions to use memory imagery placed an artificial constraint on what designers intuitively might do.

\section{Test of Hypotheses}

In this section, tests of the four hypotheses are presented. Mean scores for each dependent variable, along with standard deviations and cell sizes, appear in Table 1.

$H_{l}$ : Effect of customer incorporation and imagery type on usefulness. Consistent with $\mathrm{H}_{1}$, the ANOVA results for the usefulness variable revealed only a significant interaction effect $\left(F(2,134)=3.03, p<.05, \omega^{2}=.032\right)$. In addition, a planned contrast indicated that the designs produced in the imagination imagery, customer incorporation conditions (mean $=3.14$ ) were rated as more useful than the designs produced in the imagination imagery, no customer incorpo- ration condition $(\mathrm{F}(1,138)=6.33, p<.01$, mean $=2.64)$. $\mathrm{A}$ contrast between the designs in the memory imagery, customer incorporation condition (mean $=3.02$ ) and the memory imagery, no customer incorporation condition (mean = 3.12) was not significant $(F(1,138)<1)$. Thus, the data are consistent with $\mathrm{H}_{1}$; customer incorporation enhanced the usefulness of the designs more when imagination imagery was used than when memory imagery was used. Including the customer in memory visualization did not significantly change the outcome.

It is also noteworthy that, in the imagination imagery, customer incorporation conditions, subjects who received instruction and training produced designs that were judged the most useful (planned contrast: $\mathrm{F}(1,138)=3.60, p<.05$; means: imagination customer incorporation instruction $=2.92$, imagination customer incorporation instruction plus training $=3.35$ ).

$\mathrm{H}_{2}$ : Effect of imagery type on originality. $\mathrm{H}_{2}$ states that designers in the imagination imagery condition will produce more original product designs than those in the memory imagery condition. Consistent with $\mathrm{H}_{2}$, the ANOVA results for originality reveal only a significant main effect for imagery type $\left(\mathrm{F}(1,134)=23.35, p<.001, \omega^{2}=.159\right.$; means: memory imagery $=3.81$, imagination imagery $=4.40$ ).

$\mathrm{H}_{3}$ : Effect of customer incorporation and imagery type on appeal. The ANOVA results for the appeal variable revealed only an interaction effect $\left(\mathrm{F}(2,134)=3.22, p<.05, \omega^{2}=\right.$ .035 ). In support of $\mathrm{H}_{3}$, a planned contrast showed that the customer appeal of the designs produced by those in the imagination imagery, customer incorporation conditions (mean $=3.74)$ was greater than the customer appeal of the

Table 1

EXPERIMENT 1: TABLE OF MEANS

\begin{tabular}{|c|c|c|c|c|}
\hline $\begin{array}{l}\text { Dependent } \\
\text { Variable }\end{array}$ & $\begin{array}{c}\text { Imagery Type } \\
\text { Condition }\end{array}$ & & Incorporation & \\
\hline \multirow{3}{*}{ Usefulness } & & Control & $\begin{array}{l}\text { No customer } \\
\text { incorporation }\end{array}$ & $\begin{array}{l}\text { Customer } \\
\text { incorporation }\end{array}$ \\
\hline & Control & $\begin{array}{l}3.10 \\
\{.61\}^{\mathrm{a}}\end{array}$ & & \\
\hline & $\begin{array}{l}\text { Memory } \\
\text { Imagination }\end{array}$ & & $\begin{array}{l}3.12 \\
\{.82\} \\
2.64 \\
\{.71\}\end{array}$ & $\begin{array}{l}3.02(2.99,3.04)^{b} \\
\{.68\} \quad\{.73, .64\} \\
3.14 \quad(2.92,3.35) \\
\{.77\} \quad\{.64, .84\}\end{array}$ \\
\hline \multirow{4}{*}{ Customer Appeal } & Control & $\begin{array}{l}3.96 \\
\{.69\}\end{array}$ & & \\
\hline & $\begin{array}{l}\text { Memory } \\
\text { Imagination }\end{array}$ & & $\begin{array}{l}3.82 \\
\{.46\} \\
4.49 \\
\{.74\}\end{array}$ & $\begin{array}{ll}3.81 & (3.80,3.82) \\
\{.80\} & \{.89, .71\} \\
4.36 & (4.48,4.23) \\
\{.52\} & \{.50, .52\}\end{array}$ \\
\hline & Control & $\begin{array}{l}3.32 \\
\{.69\}\end{array}$ & & \\
\hline & $\begin{array}{l}\text { Memory } \\
\text { Imagination }\end{array}$ & & $\begin{array}{c}3.27 \\
\{.67\} \\
3.03 \\
\{1.16\}\end{array}$ & $\begin{array}{ll}3.22 & (3.12,3.31) \\
\{.72\} & \{.76, .69\} \\
3.74 & (3.82,3.65) \\
\{.86\} & \{.80, .93\}\end{array}$ \\
\hline
\end{tabular}

Note: Cell sizes are $\mathrm{n}=20$.

aThe standard deviation for each reported mean is contained in brackets.

${ }^{b}$ The means for the customer incorporation instruction and customer incorporation instruction plus training are contained in parentheses. 
designs for all the other experimental conditions combined $(\mathrm{F}(1,138)=11.63, p<.001 ;$ mean $=3.19) .^{4}$

$H_{4 a}$ and $H_{4 b}$ : The effect of usefulness and originality on appeal. The interaction effect produced by the manipulations of imagery type and customer incorporation on customer appeal $\left(\mathbf{H}_{3}\right)$ was hypothesized to be mediated by a main effect of usefulness $\left(\mathrm{H}_{4 a}\right)$ and an interaction between originality and usefulness $\left(\mathrm{H}_{4 b}\right) .{ }^{5}$ According to Baron and Kenny (1986), three conditions must be met to infer mediation: First, the independent variables must have a significant effect on the mediators and the ultimate dependent variable. Second, when the effects of the independent variables on the mediator variables are covaried out, the effects of the independent variables on the dependent variable should either diminish or disappear. Third, the covariates used in the analysis should be significant.

As we have shown, the independent variables have significant effects on both the mediators $\left(\mathrm{H}_{1}\right.$ and $\left.\mathrm{H}_{2}\right)$ and on customer appeal $\left(\mathrm{H}_{3}\right)$. To satisfy the second and third criteria for mediation (Baron and Kenny 1986), we needed to conduct an analysis of covariance with imagery type, customer incorporation, their interaction, and the hypothesized mediator variables as covariates. When an interaction term is hypothesized as a mediator, as in this case, Aiken and West (1990) recommend that (1) we incorporate all the direct effects; in our case, this means including the direct effect of originality beyond the hypothesized effects and (2) given that all of the effects must be included, the mediator variables should be mean centered to reduce multicollinearity. Following their recommendations, the raw usefulness and originality scores were mean centered, and the ANCOVA model estimated included the direct effect of usefulness, the direct effect of originality, and their interactive effect as covariates.

Consistent with the criteria proposed by Baron and Kenny (1986), the analysis of covariance revealed that the previously significant interaction effect $(\mathrm{F}(2.114)=3.06, p<$ $.05)$ of imagery type and customer incorporation on customer appeal disappeared $(\mathrm{F}(2,111)=2.32, p>.10)$. Furthermore, usefulness as a covariate was significant $(\mathrm{F}(1,111)=57.76, p<.001)$, as was the interactive effect be tween usefulness and originality, albeit at a $p<.10$ level $(F(1,111)=2.93)$. Thus, all three criteria required to infer mediation are met, providing support for both $\mathrm{H}_{4 \mathrm{a}}$ and $\mathrm{H}_{4 \mathrm{~b}}$.

\section{EXPERIMENT 2}

Experiment 2 attempts to test the generalizability of the findings of the first study. In the first study, we had chosen a target segment very different than the designers, namely seniors. In this study, we wanted to examine whether decreasing the difference between the designer and the segment for which they were designing attenuated the effect of the customer incorporation manipulation. We selected a target segment that was similar to the designers in an important

tWhen performed separately, the contrasts between this condition and the other conditions were all significantly different at the .05 level. Moreover. the other conditions did not differ signiticantly from one another.

sWe test for mediation using a sequential approach most commonly used in experimental research. namely, the one suggested by Baron and Kenny (1986). An alternative approach would be simultaneous path analysis (e.g. LISREL). way, but not exactly the same as the designers, because our interviews had shown that designers sometimes use images of themselves when designing products. Using a target segment identical to the designers would not allow for us to separate the effects of including the self from those of including the customer in the visualization. Therefore, we chose a sample of young women (age 20 to 24 years), because all the designers in the sample used in this study were young men. The designers were therefore similar to the target segment in terms of an important demographic characteristic, age, but differed on another, gender. In this study, we also used a different product from that used in the first study, a decision driven by a concern for generalizability.

The study used a $2 \times 2$ between-subjects factorial design with imagery type (memory and imagination) and customer incorporation (no customer incorporation and customer incorporation) as the two independent factors. Seventy-three designers participated in the study. Designers were senior undergraduate engineering students who had completed design coursework.

\section{Method}

As we discussed previously, this study differed from the first study in two important ways. First, the product chosen for the design task was an umbrella. Second, the target customers were young women. The dependent measures and manipulation checks used in the second study were similar to those used in the first study. A target sample of judges, composed of young women, was used to evaluate the produced designs. Similar to the first study, a separate sample of judges was used to evaluate originality $(n=19)$, usefulness $(n=19)$, and customer appeal $(n=20)$.

\section{Results}

Preliminartanalyses. Manipulation checks indicated success of both the imagery type $(\mathrm{F}(1,69)=3.17, p<.05)$ and the customer incorporation $(\mathrm{F}(1,69)=23.87, p<.001)$ manipulations. Reliability analysis for the ratings of the customer judges indicated satisfactory reliability for each of the measured constructs (all alphas $>.70$ ). Confirmatory factor analysis showed that a three-factor model provided a good fit for the data $\left(\mathrm{NFI}=.918, \mathrm{CFI}=.934, \chi^{2}(25)=114.23\right.$, $p<.001)$. Consequently, as in the first study, mean scores across the three items were used as the dependent measures in the analyses. Mean scores for each dependent variable, along with standard deviations and cell sizes, are presented in Table 2.

Test of hypotheses. Consistent with $\mathrm{H}_{1}$, an ANOVA for the usefulness variable revealed only an interaction effect $\left(\mathrm{F}(1,69)=5.75, p<.05, \omega^{2}=.060\right)$. A planned contrast indicated that the designs produced in the imagination imagery, customer incorporation condition were rated as more useful (mean $=3.51)$ than the designs produced in the imagination imagery, no customer incorporation condition $(\mathrm{F}(1,71)=$ $9.28, p<.01$, mean $=2.85$ ). A contrast between the memory imagery, customer incorporation condition (mean $=3.15$ ) and the memory imagery, no customer incorporation condition was not significant $(F(1,71)<1$, mean $=3.23)$. Thus, the data again support $\mathrm{H}_{1}$.

In support of $\mathrm{H}_{2}$, the ANOVA results for originality revealed only a significant main effect for imagery type 
Table 2

EXPERIMENT 2: TABLE OF MEANS

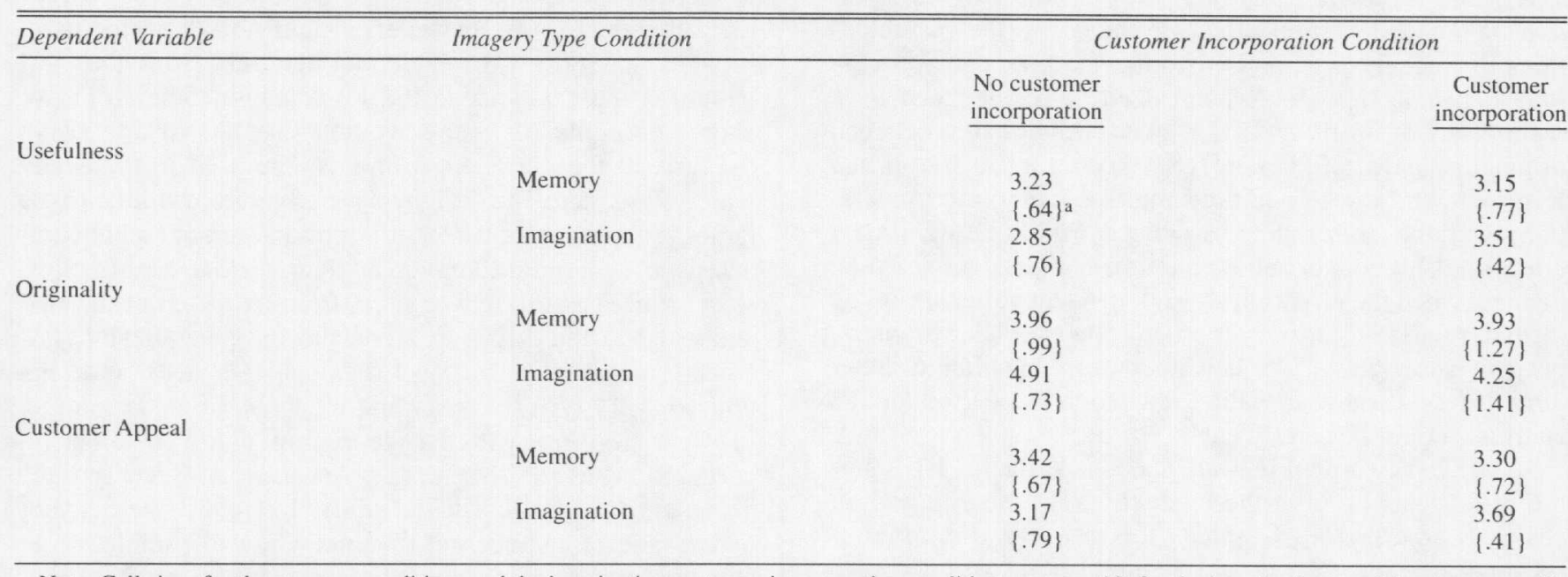

Note: Cell sizes for the memory conditions and the imagination customer incorporation condition were $\mathrm{n}=18$; for the imagination condition it was $\mathrm{n}=19$.

aThe standard deviation for each reported mean is contained in brackets.

$\left(\mathrm{F}(1,69)=5.90, p<.05, \omega^{2}=.062 ;\right.$ means: memory $=3.94$ imagination $=4.59$ ).

The ANOVA results for customer appeal revealed only an interaction effect $\left(F(1,69)=4.18, p<.05, \omega^{2}=.042\right)$. In support of $\mathrm{H}_{3}$, the planned contrast between the imagination imagery, customer incorporation condition (mean $=3.69$ ) and all the other experimental conditions combined was significant $(F(1,71)=4.71, p<.05$, mean $=3.30) .6$

Following the criteria proposed by Baron and Kenny (1986) and Aiken and West (1990), originality and usefulness were tested as mediators of the effect of imagery type and imagery content on customer appeal. In support of both $\mathrm{H}_{4 \mathrm{a}}$ and $\mathrm{H}_{4 \mathrm{~b}}$, an analysis of covariance showed that the previously significant interaction effect $(F(1,69)=4.18, p<$ $.05)$ of imagery type and customer incorporation on customer appeal $\left(\mathrm{H}_{3}\right)$ disappeared $(\mathrm{F}(\mathrm{l}, 66)<\mathrm{l})$. In addition, usefulness as a covariate was significant $(\mathrm{F}(1,66)=164.40$, $p<.001)$, as was the interactive effect between usefulness and originality, albeit at a $p<.10$ level $(F(1,66)=2.81)$.

\section{DISCUSSION}

The results of both studies are consistent and lend support to the intuition that the type and content of visual mental imagery play important roles in the design process for new products. The findings support our conceptual framework for how visual mental imagery can influence relevant aspects of a design.

Consistent with the proposed hypotheses, the results indicate that including the customer in imagination visual imagery during the design process has a greater effect on the

\footnotetext{
6When performed separately, the contrasts between the imagination, customer incorporation condition (mean $=3.69$ ), the memory. customer incorporation condition (mean $=3.31$ ), and the imagination, no customer incorporation condition (mean $=3.17$ ) were significantly different at the .05 level. The contrast between the imagination. customer incorporation condition and the memory, no customer incorporation condition (mean $=3.42$ ) was marginally different $(p<.10)$. The other conditions did not differ significantly from one another.
}

usefulness of the designs produced than including the customer in memory visual imagery. Interestingly, the use of imagination imagery, when it is not focused on the customer, leads to designs that are less useful than those in any of the other conditions. The findings also show that imagery based on imagination results in more original designs than imagery based on memory. Designs produced when visual images of the customer are incorporated in imagination imagery also are shown to be more appealing to the customer. The effects on customer appeal are mediated by both the perceived usefulness of the design and its originality.

The effect sizes for the ANOVAs, as reflected by the $\omega^{2}$ statistic obtained across both studies, ranged between 032 and .159. According to Cohen (1977), a "large" effect produces an $\omega^{2}$ value of .15 or greater. A "medium" effect is .06 , and a "small" effect is .01. Thus, but for the main effect of originality in the first study, which was large (.159), all the other effect sizes would be considered moderate. Therefore, we believe that the variables we studied are not only important, but also explain a reasonable portion of the variance in the data.

Our research has a number of limitations. Because of experimental approach, we had to make choices about the variables to include and were not able to study all the variables on which our results might be contingent. In the product design context, we might expect that the characteristics of the designer (e.g., level of experience, ability to visualize, working individually or in a team), the designer-market interface (e.g., the similarity between the designer and the target segment), the product being designed (e.g., product for an end user [i.e., a can opener] versus a component [i.e., a ball bearing]), and the nature of the design task (e.g., time provided, scope of design mission) might influence the relationships observed in this research. The research reported here used student designers working individually on a design concept for a consumer product with a short time limit. In our two studies, the similarity between the designer and the target market varied, as did the product that was designed, but the results were the same. This provides some support for the 
robustness of our conceptual framework and findings across different product design situations.

Our interviews with designers suggest that they often work individually, design products for a range of target segments, and are given a variety of design missions, including the development of design concepts similar to those used in this research. They also work with serious time constraints, often with less than a day allocated to concept-generation tasks. Therefore, our results should have relevance for at least some of the situations that designers face. However, more research, varying the factors previously identified, is necessary to establish the generalizability of our findings to a broader range of product design contexts.

A further opportunity for research is the identification of dependent measures that may influence customer appeal, other than originality and usefulness. In our research, we focused on concept design, an early stage in the new product development process. Perhaps at a later stage in product development, other factors (e.g., reliability, economic cost) would be important in generating customer appeal.

This research adds to the marketing and design literature in several ways. Foremost, we develop a theoretical framework that identifies two factors, type and content of imagery, that are important in the context of designing new products. The distinction between types of imagery has been made previously (e.g., Childers and Houston 1983), but this is the first attempt to study different types of imagery empirically and show the value of the distinction in a marketing context. The importance of the customer also has been recognized in the marketing literature (e.g., Blattberg and Deighton 1996), but, as the innumerable anecdotes about marketing failures indicate, it is difficult to implement a customer focus. Our results suggest that the feeclback the designers obtain from visualization enhances the customer appeal of the products designed. Thus, our research provides a mechanism for keeping the customer front and center during the design process. Finally, our results suggest two additional important roles for marketers in the design process. First, the marketer must specify the target segment precisely, so that the right kind of customer can be visualized. Second, the marketer should provide those insights about customers and their behavior that facilitate the designer's ability to visualize the customer.

\section{REFERENCES}

Adeyemo, S.A. (1990), "Thinking Imagery and Problem-Solving," Psychological Studies, 35 (3), 17990.

(1994), "Individual Differences in Thinking and Problem Solving," Personality and Individual Differences, 17 (1), $117-24$.

Aiken, Leona S. and Stephen G. West (1990). Multiple Regression: Testing and Interpreting Interactions. Newbury Park, CA: Sage Publications

Andrews, Jonlee and Daniel C. Smith (1996), "In Search of the Marketing Imagination: Factors Affecting the Creativity of Marketing Programs for Mature Products," Journal of Marketing Research, 33 (2), 174-87.

Angelmar, Reinhard (1990), "Product Innovation: A Tool for Competitive Advantage," European Journal of Operational $R e^{-}$ search. 47 (2). 182-89.

Bahrami, Ali and Cihan H. Dagli (1994). "Design Sicience," in Intelligent Systems in Design and Manufacturing, Cihan H. Dagli and Andrew Kusiak, eds. New York: ASME Press, 7-25.
Bailetti, Antonio J. and Paul F. Litva (1995), "Integrating Customer Requirements into Product Designs," Joumal of Product Innovation Management, I2 (1), 3-15.

Baron, Reuben M. and David A. Kenny (1986), "The Moderator-Mediator Variable Distinction in Social Psychological Research: Conceptual, Strategic, and Statistical Considerations," Journal of Personality and Social Psychology, 51 (6), 1173-82.

Baxter, Mike (1995), Product Design. New York: Chapman and Hall.

Bentler, P.M. and D.G. Bonett (1980), "Significance Tests and Goodness of Fit in the Analysis of Covariance Structures," Psychological Bulletin, 88 (3), 588-606.

Besemer, Susan and Karen O'Quin (1986), “Analyzing Creative Products: Refinement and Test of a Judging Instrument," The Journal of Creative Behavior, 20 (2), 115-26.

Blattberg, Robert C. and John Deighton (1996), "Manage Marketing by the Customer Equity," Harvard Business Review, 74 (July/August), 136-44.

Bloch, Peter H. (1995), "Seeking the Ideal Form: Product Design and Consumer Response," Journal of Marketing, 59 (July), 16-29.

BusinessWeek (1993), "Flops," (August 16), 76-82.

Childers, Terry L. and Michael J. Houston (1983), "Imagery Paradigms for Consumer Research: Alternative Perspectives from Cognitive Psychology," in Advances in Consumer Research, Vol. 10, Richard P. Bagozzi and Alice M. Tybout, eds. Provo, UT: Association for Consumer Research, 59-64.

Cohen, Jacob (1977), Statistical Power Analysis for the Behavioral Sciences. New York: Academic Press.

Cooper, Robert G. and E.J. Kleinschmidt (1987), “New Products: What Separates Winners from Losers?" Journal of Product Innovation Management, 64 (3), 169-84.

- and - (1990), "New Product Success Factors: A Comparison of 'Kills' Versus Successes and Failures," $R \& D$ Management, 20 (1), 47-63.

Crawford, C. Merle (1987), "New Product Failure Rates: A Reprise," Research Management, 30 (4), 20-24.

Davidson, J.H. (1976), "Why Most New Consumer Brands Fail," Harvard Business Re'view. 54 (March/April), 117-22.

Deshpandé, Rohit, John U. Farley, and Frederick E. Webster (1993), "Corporate Culture. Customer Orientation, and Innovativeness in Japanese Firms: A Quadrad Analysis," Journal of Marketing, 52 (January), 23-36

Downing, Francis (1992), "Image Banks: Dialogues Between the Past and the Future," Environment and Behavior, 24 (4), 441-70.

Dumaine, Brian (1991), "Design that Sells and Sells and...," For tune, (March 11), 86-94.

Ellen, Pam S. and Paula F. Bone (1991), "Measuring Communication-Evoked Imagery Processing." in Advances in Consumer Research. Vol. 18, Rebecca H. Holman and Michael R. Solomon, eds. Provo, UT: Association for Consumer Research, $806-12$.

Elstrom, Peter (1996), "PDA May Always Mean Pretty Darn Average," Business Week, (June 24), 110.

Finke, Ronald. Thomas B. Ward, and Steven M. Smith (1992), Creative Cognition: Theory, Research, and Applications. Cambridge, MA: MIT Press.

French, Michael (1994), Invention and Evolution: Design in Na. ture and Engineering. New York: Cambridge University Press.

Griffin, Abbie and John R. Hauser (1993), “The Voice of the Consumer," Marketing Science, 12 (1), 1-25.

Horowitz, Mardi J. (1983), Image Formation and Psychotherapy. New York: Jason Aronson.

Jansson, David G. and Steven Smith (1991), "Design Fixation," Design Studies, 12 (1), 3-11

Johnson, Bradley (1993). "Nuts About Newton? Nah!" Ad Age, 64 (44), 3.53 . 
Kardes, Frank R. (1986), "Effects of Initial Product Judgements on Subsequent Memory-Based Judgements," Journal of Consumer Research, 13 (June), 1-11.

Keppel, Geoffrey (1991), Design and Analysis: A Researcher's Handbook, 3d ed. Englewood Cliffs, NJ: Prentice Hall.

Kosslyn, Stephen Michael (1994), Image and Brain. Cambridge, MA: MIT Press.

Kotler, Philip and G. Alexander Rath (1984), "Design: A Powerful but Neglected Strategic Tool," Journal of Business Strategy, 5 (Fall), 16-2l.

Leonard, Dorothy and Jeffrey F. Rayport (1997), "Spark Innovation Through Empathic Design," Harvard Business Review, 75 (November/December), 102-13.

Lorenz, Christopher (1990), The Design Dimension: The New Competitive Weapon for Product Strategy and Global Marketing. Cambridge, MA: Basil Blackwell.

MacInnis, Deborah J. and Linda L. Price (1987), "The Role of Imagery in Information Processing: Review and Extensions," Journal of Consumer Research, 13 (March), 473-91.

Mano, Haim and Richard C. Oliver (1993), "Assessing the Dimensionality and Structure of the Consumption Experience: Evaluation. Feeling, and Satisfaction," Journal of Consumer Research, 20 (December), 451-66.

Morris, Peter E. and Peter J. Hampson (1983), Imagery and Consciousness. New York: Academic Press.

Oakley, Mark (1990), Design Management: A Handbook of Issues and Methods. Cambridge, MA: Blackwell Reference.

Ogden, R.M. (1913), "Experimental Criteria for Differentiating Memory and Imagination in Projected Visual Images," Psychological Review, 20 (5), 378-410.

Olney, Thomas J., Morris B. Holbrook, and Rajeev Batra (1991), "Consumer Responses to Advertising: The Effects of Ad Content, Emotion, and Attitude Toward the Ad on Viewing Time," Joumal of Consumer Research, 17 (March), 440-53.

Orr, Joel N. (1993), "Almost Is Not Enough," Computer-Aided Engineering, $12(9), 42-43$.

Palmiter, Susan. Gene Lynch, Scott Lewis, and Mark Stempsti (1994), "Breaking Away from the Conventional Usability Lab: The Customer-Centered Design Group at Tektronix. Inc.." Behaviour and Information Technolog: 13 (1,2), 128-31.
Perky, C.W. (1910). "An Experimental Study of Imagination," American Journal of Psychology, 21 (3), 422-52.

Pugh, Stuart (1996), Creating Innovative Products: Using Total Design. Don Mills, ON: Addison-Wesley Publishing Company. Richardson, Alan (1969), Mental Imagery. New York: Springer. (1983), "Imagery: Definition and Types," in Imagery: Current Theory, Research and Application, Aness Sheik, ed. New York: John Wiley \& Sons, 3-42.

Rifkin, Glenn (1994), "Product Development: Empathic Design Helps Understand Users Better," Harvard Business Review, 72 (2), 10-11.

Roozenburg, N.F.M. and J. Eekels (1995), Product Design: Fundamentals and Methods. Toronto, ON: John Wiley \& Sons.

Roskos-Ewoldsen, Beverly (1993), "Discovering Emergent Properties of Images," in Imagery, Creativity, and Discovery: A Cognitive Perspective, Beverly Roskos-Ewoldsen, Magaret Jean Intons-Peterson, and Rita E. Anderson, eds. Amsterdam, Netherlands: North-Holland Elsevier, 223-54.

Smith, Steven M., Thomas B. Ward, and Jay S. Schumacher (1993), "Constraining Effects of Examples in a Creative Generation Task," Memory and Cognition, 21 (6), 837-45.

Song, X. Michael and Mark E. Parry (1997). "The Determinants of Japanese New Product Successes," Journal of Marketing Research, 34 (February), 64-76.

Ulrich, Karl T. and Steven D. Eppinger (1995), Product Design and Development. New York: McGraw-Hill.

Urban, Glen L. and John R. Hauser (1993), Design and Marketing of New Products, 2d ed. Englewood Cliffs, NJ: Prentice Hall. and Eric Von Hippel (1988), "Lead User Analyses for the Development of New Industrial Products," Management Science, 34 (5), 569-82.

Von Hippel, Eric (1978), "Successful Industrial Products from Customer Ideas," Journal of Marketing, 42 (1), 39-49.

(1986), "Lead Users: A Source of Novel Product Concepts," Management Science, 32 (7), 791-805.

Weiman. Liza and Tom Moran (1992), "Newton: A Step Toward the Future," MacWorld, 9(8), 129-31.

Wind, Jerry and Vijay Mahajan (1997), "Issues and Opportunities in New Product Development: An Introduction to the Special Issue," Journal of Marketing Research. 34 (February). 1-12. 